\title{
Non-Association of Methylenetetrahydrofolate Reductase (MTHFR) Polymorphisms with Homocysteine Levels, Venous or Arterial Thromboses in 1,141 North-Central Appalachian Patients
}

\author{
Farhad Khimani ${ }^{1}$, Peter L. Perrotta ${ }^{2}$, Gerry R. Hobbs $^{3}$, \& Thomas F. Hogan ${ }^{1}$ \\ ${ }^{1}$ Departments of Medicine, West Virginia University School of Medicine, Morgantown, WV, United States \\ ${ }^{2}$ Pathology, West Virginia University School of Medicine, Morgantown, WV, United States \\ ${ }^{3}$ Community Medicine \& Statistics, West Virginia University School of Medicine, Morgantown, WV, United \\ States \\ Correspondence: Thomas F Hogan, Professor of Medicine, West Virginia University HSC Box 9162; \\ Morgantown. E-mail: thogan@hsc.wvu.edu
}

Received: March 27, 2016

Accepted: April 14, $2016 \quad$ Online Published: August 22, 2016

doi:10.5539/cco.v5n2p21

URL: http://dx.doi.org/10.5539/cco.v5n2p21

\begin{abstract}
Objectives: MTHFR polymorphism testing has been used by clinicians for thrombophilia risk assessment. We questioned the utility of such testing.

Methods: 1,141 patients age 18 and above had MTHFR testing for both C677T and A1298C polymorphisms, 2006 through 2012. Available plasma homocysteine levels were obtained and ICD-9 billing codes were grouped to identify venous or arterial clots in these patients.
\end{abstract}

Results: 901 women and 240 men were tested; median age in women was 33 years (range 18-86); median age in men was 47 years (range 18-83). County of residence mapping confirmed that this MTHFR tested population was from north-central Appalachia. Only $144(13 \%)$ of the 1,141 patients had no polymorphism at either the C677T or the A1298C locus; only 4 patients $(0.4 \%)$ had 3 or more polymorphisms; 993 patients (87\%) had either one or two polymorphisms.

We found polymorphism frequency pattern similar in both sexes. Although men had higher homocysteine levels, MTHFR polymorphisms did not associate with homocysteine levels in either sex. In 901 women tested, the ICD-9 coded incidence of arterial clots was 20\%, and of venous clots was 21\%; in 240 men tested, the incidence of arterial clots was $48 \%$ and of venous clots was $40 \%$. MTHFR polymorphisms did not associate with arterial or venous clots in either sex.

Based on CPT billing codes, a minimal cost estimate was $\$ 137,000$ for performing these 1,141 MTHFR tests.

Conclusions: MTHFR testing was costly and did not add useful information during thrombophilia evaluation in this patient population.

Keywords: Appalachia, embolism, homocysteine, MTHFR, polymorphism, thrombosis
Abbreviations
Hcy: homocysteine levels in micromoles per liter
ICD-9: international classification of diseases version 9
MTHFR: methylenetetrahydrofolate reductase
WVUH: West Virginia University Hospital

CPT: current procedural terminology of the American Medical Association

\section{Introduction}

Associating MTHFR polymorphisms with thrombosis or embolism has been controversial, and there is a growing consensus that MTHFR genetic testing should not be done for thrombophilia evaluation [USPSTF 2009, Leewood 2012; Hickey et al., 2013]. 
When we noted that $~ 90 \%$ of patients referred to our benign hematology clinic at West Virginia University Hospital (WVUH) had MTHFR polymorphisms [Gadiyaram et al., 2009], we decided to study all patients tested for both MTHFR C677T and A1298C polymorphisms at WVUH from 2006 through 2012, comparing the test results with homocysteine levels and ICD-9 codes identifying venous or arterial clots in the same tested patients.

\section{Methods}

During this Institutional Review Board approved study, the WVUH clinical laboratory information system (Sunquest, Tucson, AZ) identified all adult patients, age 18 and above, who had MTHFR testing during the years 2006 through 2012. In this case-based study, each individual patient had one episode of MTHFR testing and all patients were tested for both C677T and A1298C polymorphisms. Testing for MTHFR mutations was performed by direct mutation analysis using PCR amplification, signal generation, and release by cleavage of sequence-specific alleles (Invader MTHFR 677, Invader MTHFR 1298, Invader Plus Chemistry, Hologic, Madison, WI). The clinical laboratory system also searched for the highest plasma homocysteine level obtained in these same patients.

Patient County of residence at time of testing was identified and mapped. The hospital patient information system (EPIC, Madison, WI) was screened using multiple ICD-9 billing codes (listed in the Appendix) to identify venous or arterial clots occurring in these MTHFR tested patients. ICD-9 codes for many types of arterial clots were considered in aggregate as "arterial" and those for venous clots and emboli were considered in aggregate as "venous" (see Appendix). Individual patients were scored as having arterial clots, venous clots, or any clot.

Results were tabulated and analyzed using JMP V11 (SAS Inst. Inc., Cary, NC). Basic frequencies and percentages were calculated for demographics and other variables. Cross tabulations, correlations and t-tests were planned, if potential associations between variables were noted.

\section{Results}

The county of residence of the WVUH patient population having both MTHFR C677T and A1298C testing is shown in Figure 1. These patients clearly resided in the north central Appalachian region.

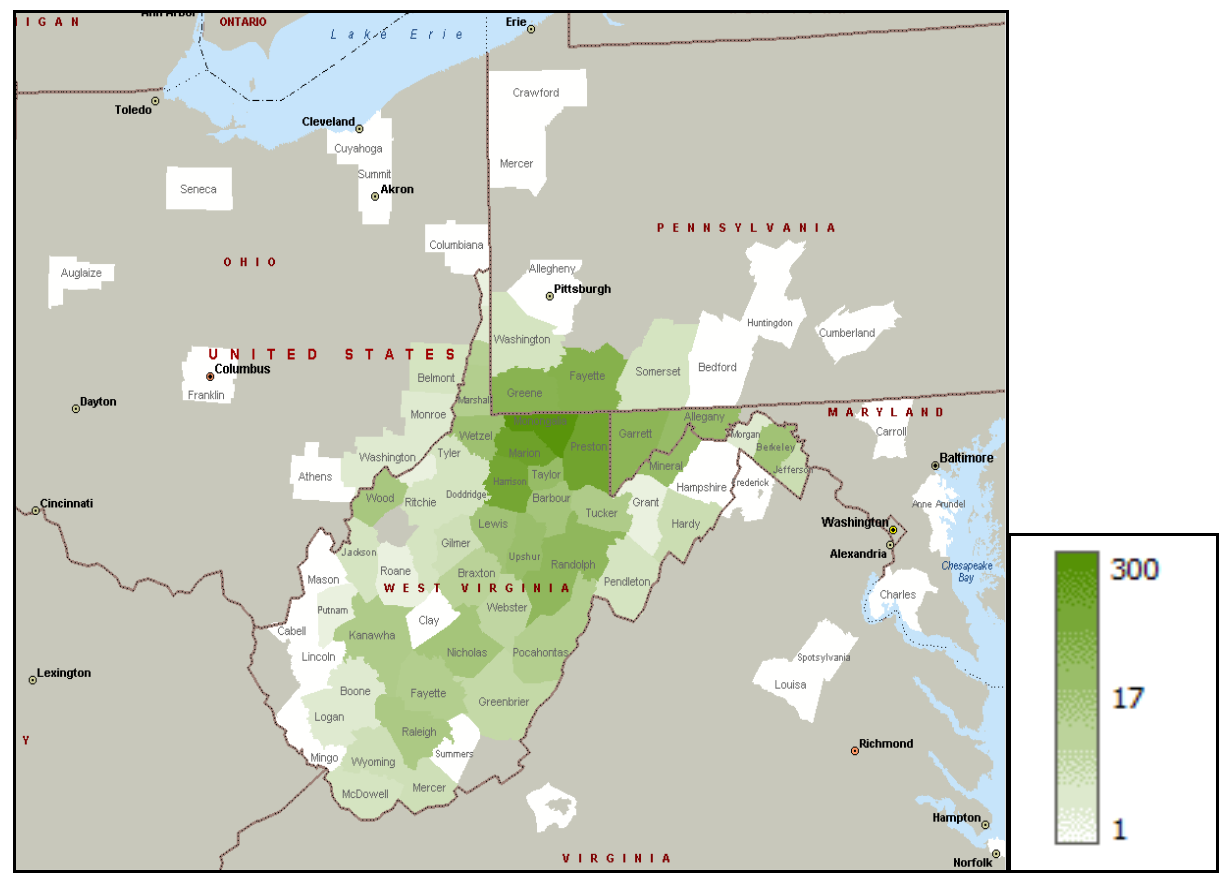

Figure 1. County of residence for MTHFR-tested patients at West Virginia University Hospital, 2006-2012

As shown in Table 1, there were 901 women and 240 men tested for MTHFR polymorphisms at both C677 and A1298 alleles. The median age in women was 33 years (range 18-86), while the median age in men was 47 years (range 18-83). Only 144 patients (13\%) had no MTHFR polymorphism, and only 4 patients $(0.4 \%)$ had 3 or more MTHFR polymorphisms, so the majority -- 993 patients (87\%) -- had 1 or 2 MTHFR polymorphisms. There was no evident difference in polymorphism frequency between men and women at either the C677 or A1298 alleles. 
Table 1. MTHFR Polymorphism Test Results in 1,141 Women and Men at West Virginia University Hospital, 2006-2012

\begin{tabular}{lllll}
\hline & & Women \# $(\%)$ & Men \# (\%) & Total \# (\%) \\
\hline C677 & A1298 & $111(12 \%)$ & $33(14 \%)$ & $144(13 \%)$ \\
C677T & A1298 & $224(25 \%)$ & $51(21 \%)$ & $275(24 \%)$ \\
C677TT & A1298 & $103(11 \%)$ & $25(10 \%)$ & $128(11 \%)$ \\
C677 & A1298C & $179(20 \%)$ & $53(22 \%)$ & $232(20 \%)$ \\
C677T & A1298C & $192(21 \%)$ & $54(23 \%)$ & $246(22 \%)$ \\
C677TT & A1298C & $1(<1 \%)$ & $1(<1 \%)$ & $2(<1 \%)$ \\
C677 & A1298CC & $91(10 \%)$ & $22(9 \%)$ & $113(10 \%)$ \\
C677T & A1298CC & 0 & $1(<1 \%)$ & $1(<1 \%)$ \\
C677TT & A1298CC & $1(<1 \%)$ & 0 & $1(<1 \%)$ \\
& Total Number & $901(79 \%)$ & $240(21 \%)$ & $1,141(100 \%)$ \\
& Age, median (range) & 33 yr $(18-86)$ & 47 yr $(18-83)$ & \\
\hline
\end{tabular}

As shown in Table 2, ICD-9 coded arterial or venous clots were compared to MTHFR polymorphisms in females, in males, and in both sexes (ICD-9 codes used to assign arterial or venous clots in these patients are listed in an appendix). Also, plasma homocysteine levels were tested and available in 610 patients and these levels were compared to MTHFR polymorphisms.

Men had slightly higher median homocysteine levels than woman for all polymorphism patterns. However, when MTHFR polymorphism frequency was compared to homocysteine levels in men alone, in women alone, and in both groups combined, in no case did the median homocysteine level appear to differ according to MTHFR C677 or A1298 polymorphism pattern.

In the 901 women, a $20 \%$ incidence of arterial clots and $21 \%$ incidence of venous clots was compared to each specific MTHFR polymorphism pattern (for example, of 111 women with no polymorphism at either C677 or A1298, 25\% had arterial and 25\% had venous clots). There was no association of either arterial or venous clots in women with any MTHFR polymorphism pattern.

Similarly, in the 240 men, a $48 \%$ incidence of arterial clots and $40 \%$ incidence of venous clots was compared to each specific MTHFR polymorphism pattern and there was no association of either arterial or venous clots in men with any MTHFR polymorphism pattern.

Finally, in the entire patient population of 1,141, the $26 \%$ incidence of arterial and $25 \%$ incidence of venous clots identified by ICD-9 billing codes had no association of with any particular MTHFR polymorphism pattern (Table 2).

Table 2. MTHFR Polymorphisms vs Homocysteine (Hcy) Levels and ICD-9 Designated Arterial or Venous Clots in 1,141 Women, Men, and All Patients at West Virginia University Hospital, 2006 - 2012

\begin{tabular}{|c|c|c|c|c|c|c|c|c|}
\hline \multicolumn{2}{|l|}{ Women } & \multirow{2}{*}{$\begin{array}{ll}\# \\
111\end{array}$} & \multicolumn{2}{|c|}{ median Hcy micromole/L (range) } & \multicolumn{2}{|l|}{ Art. Clot \# (\%) } & \multirow{2}{*}{$\begin{array}{l}\text { Vein Clot \# }(\%) \\
28(25 \%)\end{array}$} & \multirow{2}{*}{$\begin{array}{l}\text { Any Clot \# (\%) } \\
42(38 \%)\end{array}$} \\
\hline C677 & A1298 & & 8 & $4-15.1$ & $28(25 \%)$ & & & \\
\hline C677T & A1298 & 224 & 9 & $3.9-36.2$ & $35(16 \%)$ & & $34(15 \%)$ & $60(27 \%)$ \\
\hline C677TT & A1298 & 103 & 8.1 & $4-42.2$ & $25(24 \%)$ & & $22(21 \%)$ & $38(37 \%)$ \\
\hline C677 & A1298C & 179 & 8.7 & $3.9-22$ & $33(18 \%)$ & & $42(23 \%)$ & $63(35 \%)$ \\
\hline C677T & A1298C & 192 & 8.5 & $3.0-44$ & $40(21 \%)$ & & $44(23 \%)$ & $69(36 \%)$ \\
\hline C677TT & A1298C & 1 & -- & -- & -- & & -- & -- \\
\hline C677 & A1298CC & 91 & 7.9 & $4.0-18.8$ & $20(22 \%)$ & & $17(19 \%)$ & $31(34 \%)$ \\
\hline C677T & A1298CC & 0 & -- & -- & -- & & -- & -- \\
\hline \multirow[t]{2}{*}{ C677TT } & A1298CC & 0 & -- & -- & -- & & -- & -- \\
\hline & Total \# & 901 & & & $181(20 \%)$ & & $187(21 \%)$ & $303(34 \%)$ \\
\hline Men & & \# & \multicolumn{2}{|c|}{ median Hcy micromole/L (range) } & Art. Clot & $\#(\%)$ & Vein Clot \# (\%) & Any Clot \# (\%) \\
\hline C677 & A1298 & 33 & 10.2 & $3.5-35$ & $17(52 \%)$ & & $9(27 \%)$ & $24(73 \%)$ \\
\hline C677T & A1298 & 51 & 9.7 & $4.5-21.1$ & $25(49 \%)$ & & $24(47 \%)$ & $38(75 \%)$ \\
\hline C677TT & A1298 & 25 & 13.6 & $9.9-63$ & $7(28 \%)$ & & $9(36 \%)$ & $15(60 \%)$ \\
\hline C677 & A1298C & 53 & 10 & $3.7-19.5$ & $24(45 \%)$ & & $24(45 \%)$ & $41(77 \%)$ \\
\hline C677T & A1298C & 54 & 10.7 & $6-22.6$ & $27(50 \%)$ & & $25(46 \%)$ & $41(76 \%)$ \\
\hline C677TT & A1298C & 1 & -- & -- & $1(<1 \%)$ & & -- & $1(<1 \%)$ \\
\hline C677 & A1298CC & 22 & 10.5 & $3.7-22$ & $12(55 \%)$ & & $6(27 \%)$ & $16(73 \%)$ \\
\hline C677T & A1298CC & 1 & -- & -- & $1(<1 \%)$ & & -- & $1(<1 \%)$ \\
\hline \multirow[t]{2}{*}{ C677TT } & A1298CC & 0 & -- & -- & -- & & -- & -- \\
\hline & Total \# & 240 & & & $114(48 \%)$ & & $97(40 \%)$ & $177(74 \%)$ \\
\hline All Patients & & $\#$ & \multicolumn{2}{|c|}{ median Hcy micromole/L (range) } & Art. Clot & $\#(\%)$ & Vein Clot \# (\%) & Any Clot \# (\%) \\
\hline C677 & A1298 & 144 & 9 & $3.5-35$ & $45(31 \%)$ & & $37(26 \%)$ & $66(46 \%)$ \\
\hline $\mathrm{C} 677 \mathrm{~T}$ & A1298 & 275 & 9 & $3.9-36.2$ & $60(22 \%)$ & & $58(21 \%)$ & $98(36 \%)$ \\
\hline C677TT & A1298 & 128 & 9 & $4.0-63$ & $32(25 \%)$ & & $31(24 \%)$ & $53(41 \%)$ \\
\hline C677 & A1298C & 232 & 9.5 & $3.7-22$ & $57(25 \%)$ & & $66(28 \%)$ & $104(45 \%)$ \\
\hline C677T & A1298C & 246 & 9 & $3.0-44$ & $67(27 \%)$ & & $69(28 \%)$ & $110(45 \%)$ \\
\hline C677TT & A1298C & 2 & -- & -- & $1(<1 \%)$ & & -- & $1(<1 \%)$ \\
\hline C677 & A1298CC & 113 & 8.3 & $3.7-22$ & $32(28 \%)$ & & $23(20 \%)$ & $47(42 \%) 1$ \\
\hline C677T & A1298CC & 1 & -- & -- & $1(<1 \%)$ & & -- & $1(<1 \%)$ \\
\hline \multirow[t]{2}{*}{ C677TT } & A1298CC & 0 & -- & -- & -- & & -- & -- \\
\hline & Total \# & 1,141 & & & $295(26 \%)$ & & $284(25 \%)$ & $480(42 \%)$ \\
\hline
\end{tabular}




\section{Discussion}

MTHFR (5, 10-methylenetetrahydrofolate reductase), an enzyme involved in homocysteine metabolism, converts folate, a cofactor for homocysteine conversion, into its major circulating form 5-methyltetrahydrofolate. Polymorphisms in the gene encoding MTHFR have been thought to influence blood levels of homocysteine, which has been considered a risk factor for venous or arterial thromboses, venous thromboembolism, myocardial infarction, and stroke. [Jacques et al., 1996; Selhub et al., 1996]

MTHFR polymorphism C677T results in a $\mathrm{C} \rightarrow \mathrm{T}$ substitution at nucleotide 677, causing thermolability of the enzyme at $37^{\circ} \mathrm{C}$. Homozygotes (C677TT) have more than 50\% reduction in enzyme activity, but the effect on homocysteine levels depends on folate intake. Homocysteine levels are about $25 \%$ higher in homozygous carriers only when plasma folate concentration is low. [Frosst et al.,1995] MTHFR polymorphism A1298C results in an $\mathrm{A} \rightarrow \mathrm{C}$ substitution at nucleotide 1298 , causing the activity of the enzyme to be decreased, but not to the same extent as the C677T polymorphism. [Weisberg et al., 1998]

In 2005, Den Heijer performed a large meta-analysis, including 8,364 cases and 12,468 controls, and found a small increase in risk for MTHFR 677TT carriers (odds ratio, 1.20; 95\% CI, 1.08-1.32) which increased in association with homocysteine levels. [Den Heijer et al., 1995]

In 2007, Bezemer performed a population based case control study with 9,231 participants, but found no association between MTHFR polymorphism and risk of venous thrombosis. [Bezemer et al., 2007]

Recently, secondary prevention trials have looked at the effect of lowering homocysteine levels with vitamin B supplementation, but have found that, despite decreased homocysteine levels in the vitamin treatment groups, none of these trials prevented recurrent venous thrombosis or recurrent cardiovascular disease. [Den Heijer et al., 2005; Bonaa et al., 2006; Lonn et al., 2006; Ray et al., 2007; Toole et al., 2004] However, many healthcare providers have continued to order MTHFR polymorphism testing as part of thrombophilia evaluations.

When we noted a $92 \%$ prevalence of MTHFR polymorphisms in 90 patients presenting to our benign hematology clinic for coagulopathy evaluation [Gadiyaram et al., 2009], we decided to study our entire MTHFR test population from 2006 through 2012.

Although a high MTHFR polymorphism prevalence (87\%) at WVUH was re-confirmed, we found no association between any MTHFR polymorphism and ICD-9 documented clots, nor did we find an association between MTHFR polymorphisms and homocysteine levels. Thus, routine MTHFR testing did not demonstrably contribute to thrombophilia risk assessment in our patient population. We think that MTHFR testing should no longer be routinely ordered for that purpose.

There are several limitations to our data. This was a single center retrospective study representing laboratory testing at one northern Appalachian University Hospital \& Clinic population [Figure 1]. The study has no available concurrent "control" group (i.e. healthy people MTHFR tested for no reason except to serve as controls). In our region, we are not aware of any appropriate control or patient population available for comparison with our data.

Since MTHFR polymorphism prevalence is known to vary worldwide, we looked at our MTHFR polymorphism prevalence versus that reported by Gueant-Rodriguez [Gueant-Rodriguez et al., 2006] and noted that our patient population appeared "European" more than "West African" or "Mexican", which agrees with West Virginia's 2011 population demographic, having only $1.3 \%$ Hispanic and 3.5\% African American ethnicity (http://quickfacts.census.gov).

Although Moll and Varga [Moll \& Varga, 2015] stated that 7-to-12\% of North Americans have an MTHFR-A1298C polymorphism, 52\% of our 1,141 patients had such a polymorphism (Table 1). The reason for, and significance of, this higher prevalence is unknown.

In this retrospective review, we found that patient selection for MTHFR testing at our center was heavily skewed, since almost $80 \%$ of the MTHFR-tested patients were women from hospital or clinic sources, and only $20 \%$ were men. Also, the MTHFR tested women were significantly younger than the men. One hypothesis for this skew is that there may be higher incidence of "pre-event" thrombophilia testing concern for young or pregnant women with history of fetal loss or high risk pregnancy, while males may more often be selected for testing after presenting "post-event" with clinically apparent clots.

The data on venous $\&$ arterial clots in these patients was extracted using ICD-9 billing codes, and we do not know the ICD-9 coding error rate at WVUH. The ICD-9 documented clots could precede or follow MTHFR testing and were not necessarily concurrent. We chose to aggregate the ICD-9 codes as "arterial" or "venous" 
(see appendix) since a much larger patient population than ours would likely be needed to investigate the significance of individual clot subtypes.

Use of anti-coagulant medications by individual patients during the study period was unknown. Also, other coagulation testing in these 1,141 patients was performed with variable frequency. For example, the factor $\mathrm{V}$ polymorphism was tested in 967 patients and $69(7 \%)$ were abnormal; the factor II polymorphism was tested in 958 patients and $46(5 \%)$ were abnormal; anti-cardiolipin $\operatorname{IgG}$ was tested in 884 patients and $28(3 \%)$ were abnormal; anti-cardiolipin IgM was tested in 887 patients and 81 (9\%) were abnormal. Plasma homocysteine levels were tested in 610 (53\%) patients (results in Table 2).

In theory, a clinical selection process for ordering a homocysteine level (or any other test) could affect the likelihood of an abnormal result, skewing results in this subpopulation and affecting any association with MTHFR polymorphisms. Also, universal folate supplementation in United States food products since 1998 may have influenced homocysteine levels in our population. In any case, we found no association of MTHFR polymorphisms with homocysteine levels in the patients tested.

\section{Conclusion}

MTHFR testing for C677T and A1298C polymorphisms in our patient population did not demonstrably contribute to thrombophilia risk assessment at this northern Appalachian University medical center. Using current procedural terminology of the American Medical Association (CPT) laboratory codes to estimate test cost, the WVUH clinical laboratory billed approximately $\$ 120$ to perform testing of both MTHFR alleles in each of 1,141 patients, for a CPT conservative cost estimate of $\$ 137,000$. Our data support the growing consensus that MTHFR testing should not be routinely ordered for thrombophilia testing [USPSTF 2009; Leawood 2012; Hickey, Curry, Toriello 2013], and we intend to bring these data to the attention of the clinicians who order these tests.

\section{Acknowledgements}

Kim Evans \& Nancy Vest, WVUH Decision Support Group, for ICD-9 coding assistance.

\section{References}

Bezemer, I. D., Doggen, C. J. M., Vos, H. L., \& Rosendaal, F. R. (2007). No association between the common MTHFR 677C->T polymorphism and venous thrombosis: results from the MEGA study. Archives of Internal Medicine, 167,497-501. http://dx.doi.org/10.1001/archinte.167.5.497

Bønaa, K. H., Njølstad, I., Ueland, \& P. M., et al., (2006). Homocysteine lowering and cardiovascular events after acute myocardial infarction. New England Journal of Medicine, 354, 1578-1588. http://dx.doi.org/10.1056/NEJMoa055227

Den Heijer, M., Lewington, S., \& Clarke, R., (2005). Homocysteine, MTHFR and risk of venous thrombosis: a meta-analysis of published epidemiological studies. Journal of Thrombosis and Hemostasis, 3, 292-299. http://dx.doi.org/10.1111/j.1538-7836.2005.01141.x

Frosst, P., Blom, H. J., \& Milos, R., et al., (1995). A candidate genetic risk factor for vascular disease: a common polymorphism in methylenetetrahydrofolate reductase. Nature Genetics, 10, 111-113. http://dx.doi.org/10.1038/ng0595-111

Gadiyaram, V. K., Khan, M. A., \& Hogan, T. F., et al., (2009). Significance of MTHFR gene polymorphism with normal homocysteine level in vascular events. Journal of Clinical Oncology (Meeting Abstracts) 2009. Available from: http://meeting.ascopubs.org/cgi/content/abstract/27/15S/e20520

Guéant-Rodriguez, R. M., Guéant, J. L., \& Debard, R., et al., (2006). Prevalence of methylenetetrahydrofolate reductase $677 \mathrm{~T}$ and $1298 \mathrm{C}$ alleles and folate status: a comparative study in Mexican, West African, and European populations. American Journal of Clinical Nutrition, 83, 701-707.

Hickey, S. E., Curry, C. J., \& Toriello, H. V., (2013). ACMG Practice Guideline: lack of evidence for MTHFR polymorphism testing. Genetics in Medicine, 15, 153-156. http://dx.doi.org/10.1038/gim.2012.165

Jacques, P. F., Bostom, A. G., \& Williams, R. R., et al., (1996). Relation between folate status, a common polymorphism in methylenetetrahydrofolate reductase, and plasma homocysteine concentrations. Circulation, 93, 7-9. http://dx.doi.org/10.1161/01.CIR.93.1.7

Leawood, K. S., (2012). American Academy of Family Physicians (AAFP). Summary of recommendations for clinical preventive services. American Academy of Family Physicians; 2012, http://www.aafp.org/dam/AAFP/documents/patient_care/clinical_recommendations /October2012SCPS.pdf. 
Accessed June 17, 2015.

Lonn, E., Yusuf, S., \& Arnold, M. J., et al., (2006). Homocysteine lowering with folic acid and B vitamins in vascular disease. New England Journal of Medicine, 354, 1567-1577. http://dx.doi.org/10.1056/NEJMoa060900

Moll, S., \& Varga, E. A., (2015). Homocysteine and MTHFR polymorphisms. Circulation, 132, 6-e9. http://dx.doi.org/10.1161/CIRCULATIONAHA.114.013311

Ray, J. G., Kearon, C., \& Yi, Q., et al., (2007). Heart Outcomes Prevention Evaluation 2 (HOPE-2) Investigators. Homocysteine-lowering therapy and risk for venous thromboembolism: a randomized trial. Annals of Internal Medicine, 146, 761-767. http://dx.doi.org/10.7326/0003-4819-146-11-200706050-00157

Selhub, J., Jacques, P. F., \& Bostom, A. G., et al., (1996). Relationship between plasma homocysteine, vitamin status and extracranial carotid-artery stenosis in the Framingham Study population. Journal of Nutrition, $126,1258 \mathrm{~S}-1265 \mathrm{~S}$.

Toole, J. F., Malinow, M. R., \& Chambless, L. E., et al., (2004). Lowering homocysteine in patients with ischemic stroke to prevent recurrent stroke, myocardial infarction, and death: the Vitamin Intervention for Stroke Prevention (VISP) randomized controlled trial. Journal of the American Medical Association, 291, 565-575. http://dx.doi.org/10.1001/jama.291.5.565

US Preventive Services Task Force (USPSTF), (2009). Using nontraditional risk factors in coronary heart disease for risk assessment. Recommendations. Rockville, MD: USPSTF; http://www.uspreventiveservicestaskforce.org/Page/Document/RecommendationStatementFinal/coronary-h eart-disease-screening-using-non-traditional-risk-factors. Accessed Dec 26, 2015.

Weisberg, I., Tran, P., \& Christensen, B., et al., (1998). A second genetic polymorphism in methylenetetrahydrofolate reductase (MTHFR) associated with decreased enzyme activity. Molecular Genetics and Metabolism, 64, 169-172. http://dx.doi.org/10.1006/mgme.1998.2714

Appendix: International classification of diseases version 9 (ICD-9) coagulation codes used, in aggregate, to identify thromboses in 1,141 MTHFR-tested patients at West Virginia University Hospital and Clinics

ICD-9 Codes for arterial clots and emboli

$\begin{array}{ll}362.31 & \text { central retinal artery } \\ 410.01 & \text { anterolat ami init episd } \\ 410.02 & \text { ami anterolateral subseq } \\ 410.1 & \text { anter ami nec episd } \\ 410.11 & \text { anter ami nec init episd } \\ 410.12 & \text { ami anterior wall subseq } \\ 410.2 & \text { mi inferolateral, unspec } \\ 410.21 & \text { inferolat ami init episd } \\ 410.22 & \text { ami inferolateral subseq } \\ 410.31 & \text { inferopos ami init episd } \\ 410.32 & \text { ami inferopost subseq } \\ 410.4 & \text { ami inferior wall } \\ 410.41 & \text { infer ami nec init episd } \\ 410.42 & \text { ami inferior wall subseq } \\ 410.5 & \text { latrl ami nec episd } \\ 410.51 & \text { latrl ami nec init episd } \\ 410.52 & \text { ami lateral nec subseq } \\ 410.61 & \text { true post infarct, init } \\ 410.7 & \text { subendo infrc episd } \\ 410.71 & \text { subendo infrc init episd }\end{array}$


410.72 subendo infarct subseq

410.8 ami nec episd

410.81 ami nec initial episd

410.82 ami nec subsequent episd

410.9 ami nos unspecified

410.91 ami unspecified site initial episode of care

410.92 ami nos subsequent episd

433 basilar art occl wo infarc

433.01 occlusion and stenosis of basilar artery with cerebral infarction

$433.1 \quad$ carotid art occ wo infarc

433.10 subclavian art

433.11 occlusion and stenosis of carotid artery with cerebral infarction

433.2 vertebral art occ wo infarct

433.21 occlusion and stenosis of vertebral artery with cerebral infarction

433.3 mult precerebral occ wo infarc

433.31 mult precerebral occ $\mathrm{w}$ infarc

433.8 other precerebral occ wo infarc

433.81 other precerebral occl $w$ infarc

433.9 precerebral occl wo infarct

433.91 precerebral occl $\mathrm{w}$ infarct

434 cerebral thrombosis without mention of cerebral infarction

434.01 cerebral thrombosis with cerebral infarction

434.9 cerebral art occ wo infarc

434.91 unspecified cerebral artery occlusion with cerebral infarction

$437.3 \quad$ circle of willis

440.0 aorta occlusion

440.8 aorto-iliac arteries

444.22 femoral art

444.22 popliteal art

444.22 tibeal art

444.89 hepatic artery

447.4 celiac axis

557 ac vasc insuff intestine

557.0 mesenteric art, inferior

557.0 mesenteric art, superior

593.81 renal arteries

$\underline{\text { ICD-9 codes for venous clots and emboli }}$

325 superior saggital sinus vein

326.35 central vein occlusion of retina

362.30 ophthalmic vein

415.11 iatrogenic pulmonary embolism and infarction 
415.12 postoperative septic pulmonary embolism

415.13 saddle embol pulmon art

415.19 other pulmonary embolism and infarction

434.1 cerebral embolism without mention of cerebral infarction

434.11 cerebral embolism with cerebral infarction

434.41 popliteal vein

451.11 phlebitis and thrombophlebitis of femoral vein (deep) (superficial)

452.00 portal vein

453.4 ac dvt/embl low ext nos

453.41 ac dvt/emb prox low ext

453.41 femoral vein

453.41 iliac vein

453.42 ac dvt/emb distl low ext

453.5 recurrent deep vein thrombosis of lower extremity

453.51 upper leg dvt (deep venous thromboembolism) chronic

453.52 lower leg dvt (deep venous thromboembolism) chronic

453.6 saphenous vein

453.81 brachial vein

453.85 subclavian vein

453.86 jugular vein

453.87 vena-cava

\section{Copyrights}

Copyright for this article is retained by the author(s), with first publication rights granted to the journal.

This is an open-access article distributed under the terms and conditions of the Creative Commons Attribution license (http://creativecommons.org/licenses/by/4.0/). 